\title{
Opposed-Piston Crankshaft System Dynamics Simulation and Durability Analysis in a Neotype Two-Stroke Diesel Engine
}

\author{
Chang Ming $\mathrm{He}^{1,2, *}$, Si Chuan $\mathrm{Xu}^{1,2}$ \\ ${ }^{1}$ School of Automotive Studies, Tongji University, Shanghai, China \\ ${ }^{2}$ Clear Energy Automotive Engineering Center, Tongji University, Shanghai, China \\ Email address: \\ xiaominggoo@163.com (Chang Ming He) \\ ${ }^{*}$ Corresponding author
}

\section{To cite this article:}

Chang Ming He, Si Chuan Xu. Opposed-Piston Crankshaft System Dynamics Simulation and Durability Analysis in a Neotype Two-Stroke Diesel Engine. American Journal of Mechanical and Industrial Engineering. Vol. 2, No. 2, 2017, pp. 54-63.

doi: 10.11648/j.ajmie.20170202.11

Received: October 27, 2016; Accepted: December 8, 2016; Published: January 16, 2017

\begin{abstract}
For the opposed-piston and opposed-cylinder (OPOC) diesel engine with higher power density, recently it has drawn even more attentions than ever in several developed countries, such USA and Germany, et al, which is regarded as a technical innovation to further reduce emission, and decrease fuel consumption, attributed to outstanding thermal efficiency and engine package downsizing. To explore the interrelation of this special crank system in concept design stage, the multibody dynamics and durability of the piston-opposed crankshaft system was investigated. Firstly the optimized function model of the unique crankshaft system in an OP2S (Opposed-piston two stroke) engine was established. Then it was to figure out the influence of all structural design parameters on OPE crankshaft averaged output torque, respectively. The calculated results show that the initial crank angle difference between inner crank web and outer crank web was the most critical contributor to elevate the averaged torque output than other structural parameters. The parametric 3D model of crankshaft system was refreshed automatically based on the optimized variables. Finally an OPE crankshaft prototype was manufactured and bend fatigue experiment was carried out in a relevant laboratory to obtain the material S-N Curve. The HCF (High Cycle Fatigue) result was indicated that the minimum safety factor on crank journal fillets can reach relevant estimation criterion without crankshaft failure occurring for an engine speed sweep.
\end{abstract}

Keywords: Opposed Piston Engine, Averaged Torque Output, Durability, High Cycle Fatigue

\section{Introduction}

It is well known that the in-line or V type of IC engine has already occupied the majority of market share and widely applied in many machinery industries. There are only a few automotive corporations still fabricate the opposed-cylinder engine, just including Porsche and Subaru [10]. One of the primary problems for the opposed-cylinder or opposed piston engine is not convenient to achieve a flexible package assembly in engine cabin. Moreover, the cylinder scuffing may occur once the piston ring not well-lubricated and high thermal load on piston top and cylinder liner. Nevertheless, as the time passing, for increasingly stricter emission regulations and higher fuel economy requirement, the conventional IC engine has suffered many new challenges from energy crisis and environmental pollution problems, because there is only a small margin to further enhance power performance but needs to maintain relatively lower fuel consumption and emission level based on present technologies. So it becomes particularly more urgent than ever to seek a technical breakthrough in IC engines.

Opposed piston or opposed cylinder engine was developed a long time ago, such as the original Boxer and Junkers engines [1], [4]. But these engines above mentioned have been withdrawn from the current market due to more stringent emission legislation release or depleting crude oil resources since the latter half of 1990s. It's worth noting that the opposed piston two-stroke diesel engine owns several intrinsic advantages, namely higher power density and thermal 
efficiency as compared to a common four-stroke diesel engine [2]. The conceptual design of OPOC (Opposed Piston and Opposed Cylinder) diesel engine was firstly proposed by FEV in 2004, which was generally treated as an excellent technology innovation or a creative redesign product in IC engine field, and completely distinguished from the conventional IC engine nowadays. Some researchers presented that the OPOC engine has lower gravity center, lighter weight and more compact structural layout or smaller engine package [3]. Hofbauer, P., et al reinvented the new configuration of OPOC diesel engine running by two-stroke operation cycle. In addition, a series of verification tests were conducted in a prototype engine. The OPOC engine is assigned to the combination of Boxer and Junker engines, which assimilates their individual merits [4], [5]. Compared with a conventional four-stroke engine, the OPOC engine may own higher thermal efficiency by a proper design arrangement and combustion calibration, because there is much less heat rejection to water jacket without a cylinder head. For an OPOC two-stroke diesel engine, the power density may be up to approximately or even over $80 \mathrm{~kW} / \mathrm{L}$, mostly the twofold of a turbocharged fourstroke diesel engine, which seems to be equivalent to a Gas Turbine engine [6], [7]. The small-sized and less components in OPOC engine will also bring about high power weight density, roughly 1.1 or even $1.2 \mathrm{~kW} / \mathrm{kg}$, attributed to the elimination of valve-train mechanism [8], [9]. On the other side, the applied forces can be cancelled out due to both opposed pistons always move in an opposite direction, so that relatively low loads will be transferred to engine block, which alleviating the block vibration that closely correlated with structural borne noise. Hence, the OPOC engine may be with better NVH (Noise, Vibration and Harshness) performance because of its wonderful self-balanced characteristics even without adding any extra balance shaft mechanism.

Engine downsizing has already evolved into the mainstream during IC engine development, which implying higher power output and lighter weight or smaller engine package [11], [12]. Many scholars started a brainstorm to put forward plenty of innovative crankshaft systems and expected to combine with the respective advantages from both two-stroke and four-stroke IC engines. On account of technology progress and development, for instance, the widespread application of high-pressure fuel injection system, turbocharger and supercharging device, it becomes possible to further improve the performance aspects of opposed piston or opposed cylinder engines. Recently, several types of opposed piston engine have been reinvented and attracted many more attentions in technically advanced institutions or developed countries, i.e. in USA and Europe [13], [14]. Hereafter, some new companies for IC engine design were established in succession, such as Ecomotor, Achates Power and Pinnacle, and even FEV and AVL were participated in redesign of OPOC engine. The relevant prototype engines were fabricated and tested [15], [16], [17]. But the prominent achievements were obtained in Ecomotor and Achates Power. The Ecomotor engineers attempted to merge the opposed piston with the opposed cylinder, namely
OPOC engine, while the Achates power improved the opposed piston engine in which with two crankshafts, and published a number of research literatures according to testing data and analytic results. In addition, the Pinnacle also exhibited the four-stroke spark-ignited 250cc single-cylinder and oppose-piston reciprocating sleeve-valve engine in 2012 [18]. However, there is almost no literature to report the investigation on crankshaft system dynamic characteristics for the opposed-piston engine in detail. In references [2], [4], [15], these authors only simply illustrated the kinematic property or force distributions for the opposed-piston cranktrain but not focus on in-depth research.

Therefore, just as demonstrated above, it is essential to explore the property of OPE crankshaft system. In order to figure out the interrelationships of structural design variables for OPE (opposed piston engine) crankshaft system, it needs to carry out plenty of crankshaft dynamic simulations to explore which parameter is most critical to engine performance, as well explaining the fundamental theoretical condition of self-balanced property and revealing the loads imposing on engine block. Finally the crankshaft durability analysis is also performed for the speed sweep based on measured data input in this paper.

\section{Mean Torque Output Model}

For the better understanding of basic principles in a OPE crankshaft system, it is required to use a mathematic tool to explore an optimal design scheme for crankshaft system in an opposed piston two-stroke diesel engine. First of all, according to the relevant design targets and kinematic features of OPE crankshaft system, it should make a series of deduces based on the physical model, and identify the relevant constraint conditions as well as mutual relations for each design variable. The physical problem will be converted into a pure mathematic solution. Finally, in terms of a proper algorithm, the optimum structural variables of OPE crankshaft system can be obtained by running the complied codes based on DOE (Design of Experiment) methodology.

It is to take the maximum average torque output as the primary optimized goal in this calculation, which can be expressed by several design variables that related to structural arrangement and customization from special customer demands, namely design constants. Other parameters should be modified and adjusted continually during optimization process, i.e. these parameters are socalled design variables. The basic motion mechanism of crankshaft system in the opposed piston engine is shown in Figure 1. The inner crank radius is $O A=R_{1}$ and outer crank radius is $\mathrm{OD}=\mathrm{R}_{2}$, inner connecting rod length $\mathrm{AB}=\mathrm{L}_{1}$, and outer connecting rod length $\mathrm{CD}=\mathrm{L}_{2}$, meanwhile the pivot angle are $\beta_{1}$ and $\beta_{2}$, respectively. The initial crank angles for inner crank web and outer crank web are $\alpha_{1}$ and $\alpha_{2}$. The $R_{1}, R_{2}, L_{1}, L_{2}, \beta_{1} \beta_{2}, \alpha_{1}, \alpha_{2}$ all are considered as design variables. For steady-state operation condition in an OPE engine, the angular velocity $\omega$ is generally a constant. By making a torque from the center of crankshaft axis, the instantaneous output torque at flywheel end can be presented 
as in formula (1). If there is no initial crank angle difference between inner crank radius and outer crank radius, thus it can yield $\alpha_{1}=\alpha_{2}$.

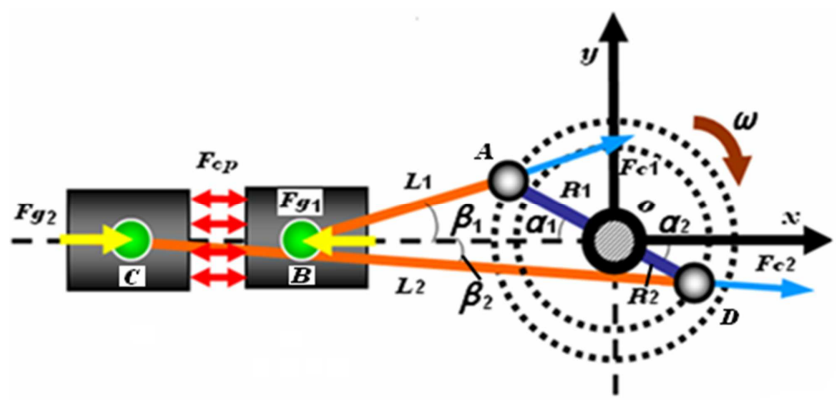

Figure 1. Main Structural Design Variables in OPE Crankshaft System.

$$
\begin{aligned}
M= & M_{1}+M_{2} \\
= & \left\{F_{c p 1} R_{1} \frac{\sin \left(\alpha_{1}+\beta_{1}\right)}{\cos \beta_{1}}+F_{g 1} R_{1} \frac{\sin \left(\alpha_{1}+\beta_{1}\right)}{\cos \beta_{1}}\right\} \\
& +\left\{F_{c p 2} R_{2} \frac{\sin \left(\alpha_{2}-\beta_{2}\right)}{\cos \beta_{2}}+F_{g 2} R_{2} \frac{\sin \left(\alpha_{2}-\beta_{2}\right)}{\cos \beta_{2}}\right\}
\end{aligned}
$$

where $F_{g 1}$ and $F_{g 2}$ are reciprocating inertia forces for inner piston and outer piston, respectively, and their expressions can be stated as following. The $M, M_{1}$ and $M_{2}$ represent the individual transient torque output for both crankshaft system.

$$
\begin{gathered}
F_{g 1}=-m_{g 1} \omega_{1}^{2} R_{1}\left(\cos \alpha_{1}+\lambda_{1} \cos 2 \alpha_{1}\right) \\
F_{g 2}=-m_{g 2} \omega_{2}^{2} R_{2}\left(-\cos \alpha_{2}+\lambda_{2} \cos 2 \alpha_{2}\right)
\end{gathered}
$$

where the $F_{c p 1}$ and $F_{c p 2}$ are gas forces produced by incylinder gas pressure acting on inner piston top and outer piston top, respectively. $m_{g 1}$ and $m_{g 2}$ are inertia mass of inner piston and outer piston. Based on the above relationships (2) and (3), hereby it can obtain the following formula (4).

$$
\begin{aligned}
M= & M_{1}+M_{2} \\
\approx & R_{1} F_{c p 1}\left(\sin \alpha_{1}+\frac{\lambda_{1}}{2} \sin 2 \alpha_{1}\right) \\
& +R_{1}\left\{-m_{g 1} \omega_{1}^{2} R_{1}\left(\cos \alpha_{1}+\lambda_{1} \cos 2 \alpha_{1}\right)\right\}\left(\sin \alpha_{1}+\frac{\lambda_{1}}{2} \sin 2 \alpha_{1}\right) \\
& +R_{2} F_{c p 2}\left(\sin \alpha_{2}-\frac{\lambda_{2}}{2} \sin 2 \alpha_{2}\right) \\
& +R_{2}\left\{-m_{g_{2}} \omega_{2}^{2} R_{2}\left(-\cos \alpha_{2}+\lambda_{2} \cos 2 \alpha_{2}\right)\right\}\left(\sin \alpha_{2}-\frac{\lambda_{2}}{2} \sin 2 \alpha_{2}\right)
\end{aligned}
$$

The averaged torque output formula $M_{m}$ of OPE crankshaft system can be derived by the integral to crank angle, just as expressed in Equation (5).

$$
\begin{aligned}
M_{m} & =\frac{1}{2 \pi} \int_{0}^{2 \pi} \sum\left(M_{c p}+M_{g}\right) d \alpha \\
& =\frac{1}{2 \pi} \int_{0}^{2 \pi} \sum M_{c p} d \alpha+\frac{1}{2 \pi} \int_{0}^{2 \pi} \sum M_{g} d \alpha
\end{aligned}
$$

However, it appears to be impossible to directly employ a generic equation to describe the in-cylinder pressure variation trend because no fixed regulation can be followed for pressure curves. Generally, in-cylinder pressure curves can be obtained by 1D thermodynamics simulation or experimental data measured through a pressure transducer. The curve smooth method is adopted here for in-cylinder gas force, which varied with crank angle. The dispersed test data can be smoothed is demonstrated in Figure 2.

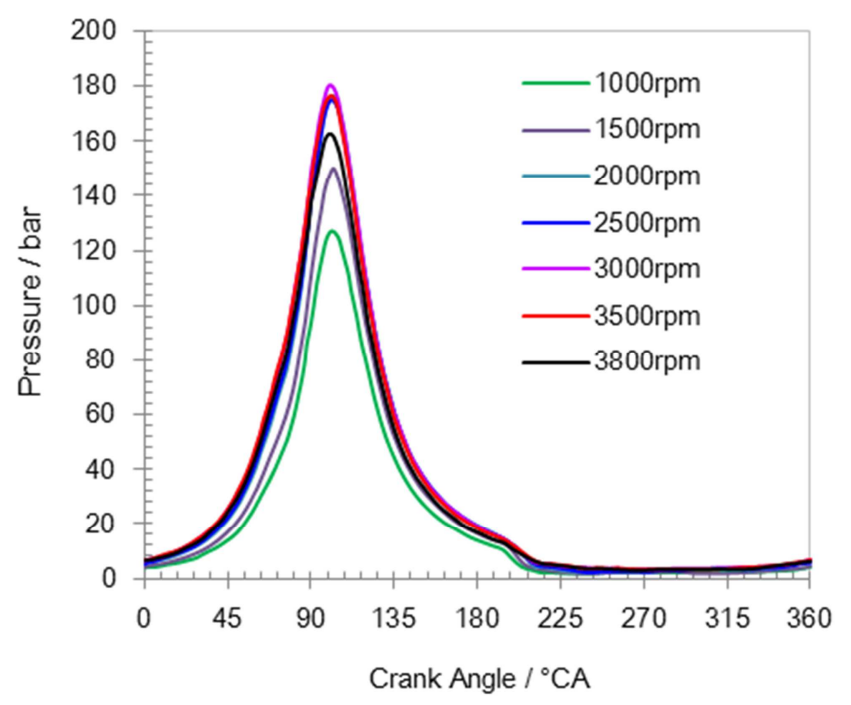

Figure 2. Curve Fitting of Gas Force Based on Test Data.

Although the motion direction of inner piston is always contrary to outer piston, the force magnitude is the same for both pistons, i.e. $F_{c p 1}=F_{c p 2}=F_{c p}(\alpha)$. Assumed that $\alpha_{1}=\alpha_{2}=\alpha$, it will yield,

$$
\begin{aligned}
M_{m} \approx & \left(R_{1}+R_{2}\right) \frac{1}{2 \pi} \int_{0}^{2 \pi} \sum_{i=1}^{7} a_{i} e^{-\left(\frac{\alpha-b_{i}}{c_{i}}\right)^{2}} \sin \alpha d \alpha \\
& +\left(\lambda_{1} R_{1}-\lambda_{2} R_{2}\right) \frac{1}{4 \pi} \int_{0}^{2 \pi} \sum_{i=1}^{7} a_{i} e^{-\left(\frac{\alpha-b_{i}}{c_{i}}\right)^{2}} \sin 2 \alpha d \alpha
\end{aligned}
$$

where $a_{i}, b_{i}$, and $c_{i}$ all are constant coefficients, $\lambda_{1} \lambda_{2}$ are inner and outer connecting rod ratio separately. From the equation (7), it can be observed that the averaged torque output of opposed piston engine is closely correlated to inner crank radius and outer crank radius and individual connecting rod ratio. The simplified form can be expressed in formula (7).

$$
M_{m}=C_{0} \cdot\left(R_{1}+R_{2}\right)+C_{1} \cdot\left(\lambda_{1} R_{1}-\lambda_{2} R_{2}\right)
$$

where,

$$
C_{0}=\frac{1}{2 \pi} \int_{0}^{2 \pi} \sum_{i=1}^{7} a_{i} e^{-\left(\frac{\alpha-b_{i}}{c_{i}}\right)^{2}} \cdot \sin \alpha d \alpha
$$

and the coefficient of 


$$
C_{1}=\frac{1}{4 \pi} \int_{0}^{2 \pi} \sum_{i=1}^{7} a_{i} e^{-\left(\frac{\alpha-b_{i}}{c_{i}}\right)^{2}} \cdot \sin 2 \alpha d \alpha
$$

The ultimate aim of optimization procedure is to maximize averaged torque output of OPE crank system, i.e. to get a maximum value for the objective function, as the formula (8).

$$
M_{m}=C_{0} \cdot\left(R_{1}+R_{2}\right)+C_{1}\left(\frac{R_{1}^{2}}{L_{1}}-\frac{R_{2}^{2}}{L_{2}}\right) \rightarrow \max
$$

The constants of $C_{0}$ and $C_{1}$ can't be solved by analytic solution method. The constants of $C_{0}$ and $C_{1}$ will be resolved through numerical integration based on the Matlab platform. It is demonstrated that two constants $\mathrm{K}_{0}, \mathrm{~K}_{1}$ and incylinder gas force, all of them are highly dependent on crank angle as shown in Figure 3.

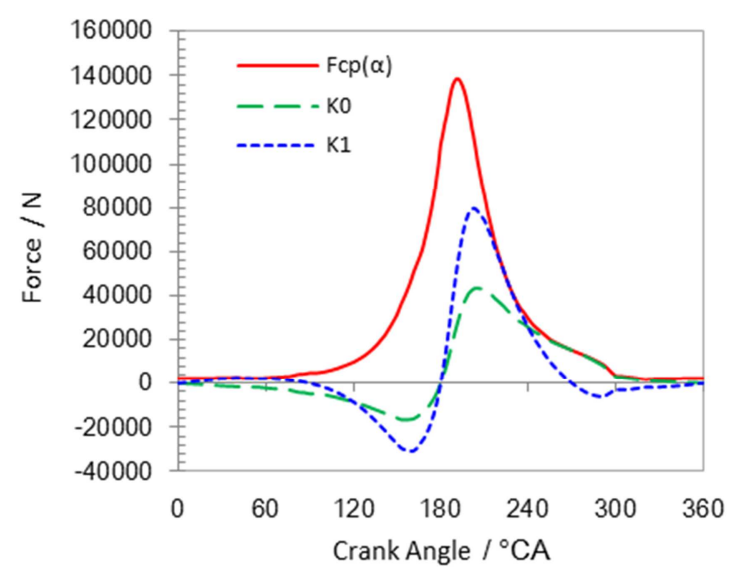

Figure 3. $C_{0}, C_{1}$ and Gas Force Curves Varied with Crank Angle.

From Figure 4 it can be found that the averaged torque will be increased linearly as with the elongation of both inner crank radius and outer crank radius, yet the engine displacement is also changed. The longer of outer crank radius, there is a larger engine package dimension that affects the length of engine block, which is unfavorable to entire engine downsizing. Therefore, it is recommended to make the inner crank radius bigger than outer crank radius in initial design stages on the premise that engine displacement remains unchanged. If cylinder displacement is fixed, the effect of inner radius and outer crank radius on mean torque output is also shown in Figure 5. It is actually conducive to torque output when with a longer inner crank radius and a shorter outer crank radius.

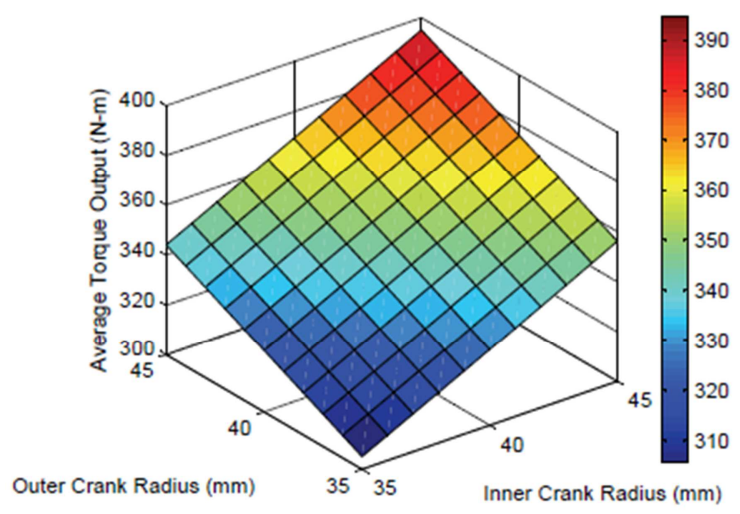

Figure 4. Averaged Torque versus Crank Radius.

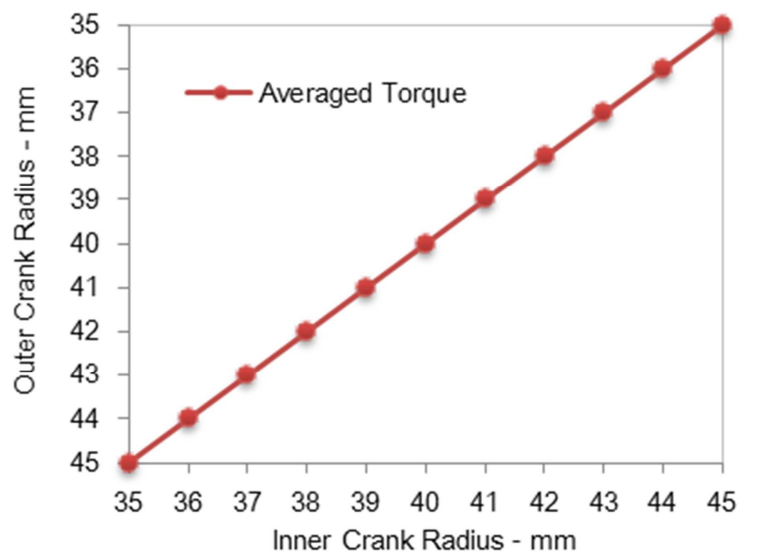

Figure 5. The Relationship between Averaged Torque and Crank Radius.

$$
\begin{aligned}
M_{m}= & \frac{1}{2 \pi} \int_{0}^{2 \pi} \sum M_{c p} d \alpha \\
\approx & \frac{1}{2 \pi} \int_{0}^{2 \pi} F_{c p}\left(R_{1} \sin \alpha+R_{2} \sin (\alpha+\Delta \alpha)\right) d \alpha \\
& +\frac{1}{2 \pi} \int_{0}^{2 \pi} F_{c p}\left(\frac{\lambda_{1} R_{1}}{2} \sin 2 \alpha-\frac{\lambda_{2} R_{2}}{2} \sin 2(\alpha+\Delta \alpha)\right) d \alpha
\end{aligned}
$$

In spite of gas force acting on piston top still can be expressed as $F_{c p 1}=F_{c p 2}=F_{c p}(\alpha)$, but $\alpha_{1} \neq \alpha_{2}$ here as described in Figure 6. The format of averaged torque should be derived by other approach because it becomes even more complicated. It is assumed that $\Delta \alpha=\alpha_{2}-\alpha_{1}$, hence $\alpha_{2}=\alpha_{1}+\Delta \alpha$. Given that $\alpha=\alpha_{1}$, thus $\alpha_{2}=\alpha+\Delta \alpha$, and then substitute it into Equation (9), the transformed format will be expressed exactly as in formula (10).

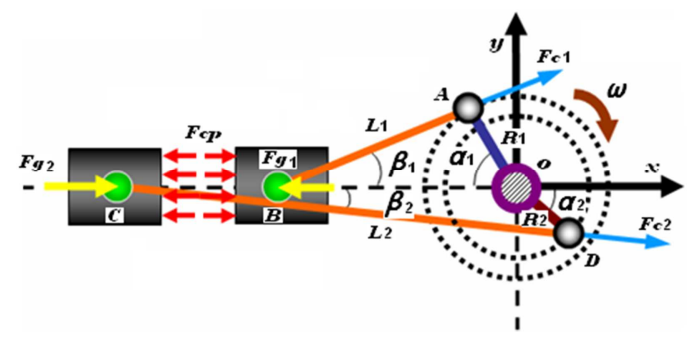

Figure 6. Initial Crank Angle Difference between Inner Crank Web and Outer Crank Web. 
From the Equation (10), the averaged torque output is closely associated with connecting rod ratio, inner crank radius and outer crank radius, and the initial crank angle difference $\Delta \alpha$ between both crank webs. Eventually, the deduced formula can be stated as below.

$$
\begin{aligned}
M_{m}= & C_{0} \cdot\left(R_{1}+R_{2} \sqrt{1-\sin ^{2} \Delta \alpha}\right) \\
& +C_{1} \cdot\left(\frac{R_{1}^{2}}{L_{1}}-\frac{R_{2}^{2}}{L_{2}}\left(1-2 \sin ^{2} \Delta \alpha\right)\right) \\
& +C_{2} \cdot\left(R_{2} \sin \Delta \alpha\right)-C_{3} \cdot \frac{2 R_{2}^{2}}{L_{2}} \sin (\Delta \alpha) \sqrt{1-\sin ^{2} \Delta \alpha}
\end{aligned}
$$

Where

$$
C_{2}=\frac{1}{2 \pi} \int_{0}^{2 \pi} \sum_{i=1}^{7} a_{i} e^{-\left(\frac{\alpha-b_{i}}{c_{i}}\right)^{2}} \cdot \cos \alpha d \alpha
$$

and the coefficient of $C_{3}$ is defined as

$$
C_{3}=\frac{1}{4 \pi} \int_{0}^{2 \pi} \sum_{i=1}^{7} a_{i} e^{-\left(\frac{\alpha-b_{i}}{c_{i}}\right)^{2}} \cdot \cos 2 \alpha d \alpha
$$

Likewise, all the constants can be obtained by the same integral method based on embedded functions in software. These integrand function of $C_{0}, C_{1}, C_{2}$, and $C_{3}$ are the $\mathrm{K} 0$, $\mathrm{K} 1, \mathrm{~K} 2, \mathrm{~K} 3$ varied crank angle, just as shown in Figure 7.

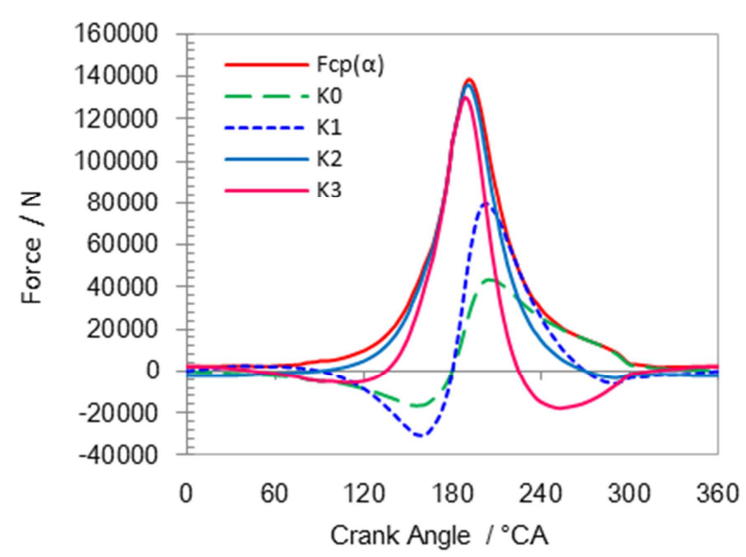

Figure 7. $K_{0}, K_{1}, K_{2}, K_{3}$ and Gas Force Varied with Crank Angle.

To increase the initial crank angle difference between inner crank web and outer crank web appears to significantly elevate the averaged torque output of opposed-piston engine with the specified engine displacement, which shown in Figure 8 . But as the rising of initial crank angle difference, it will result in the change of relative position of minimum clearance between inner piston and outer piston at TDC (Top Dead Center). The allowable value is normally below $30^{\circ} \mathrm{CA}$, i.e. $\mathrm{t}=\sin \Delta \alpha=0.5$. Once over 0.5 , it may be impossible to create the geometric solid model or achieve enough structural strength of crankshaft, additionally leading to the decrease of engine displacement. It may be concluded that initial crank angle difference should be taken as a most vital structural design variable, because it is extremely sensitive to averaged torque output in an OPE engine.

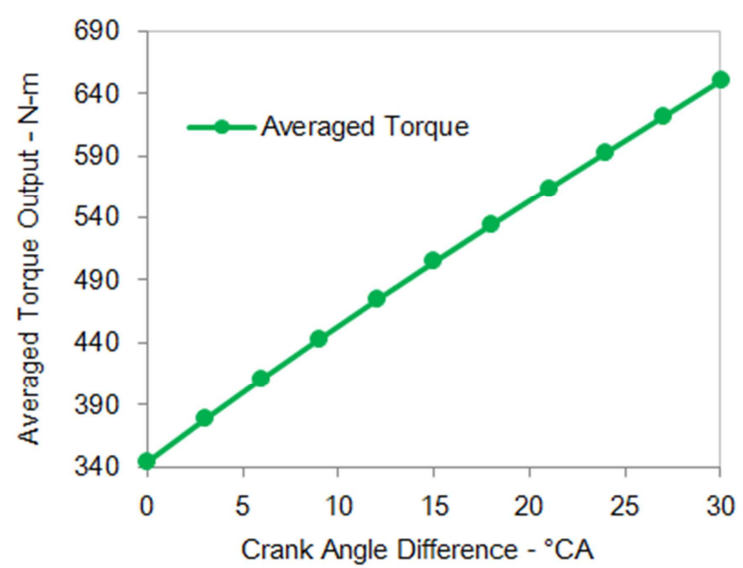

Figure 8. The Effect of Initial Crank Angle Difference on Averaged Torque Output.

Currently, if assuming that initial crank angle difference is with a fixed value, it is only to takes into account the influence of crankshaft axis offset on averaged torque output. In this case, it will bring about the alterations of relevant constraint and averaged torque formula. The crankshaft axis offset is defined in Figure 9, and the modified equation of averaged torque can be derived through some simple manipulations.

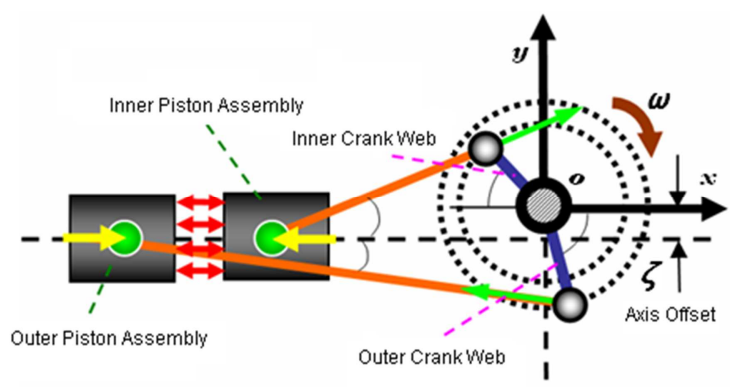

Figure 9. The Axis Offset of Crankshaft Rotation Center.

In Equation (11), it is observed that the averaged torque output highly replies on the following parameters, such as inner connecting rod ratio and outer connecting rod ratio, initial crank angle difference between both crank radiuses, and crankshaft axis offset relative to cylinder centerline.

$$
\begin{aligned}
M_{m}= & \frac{1}{2 \pi} \int_{0}^{2 \pi} \sum M_{c p} d \alpha \\
\approx & \left(R_{1}+R_{2} \cos \Delta \alpha-\lambda_{2} \zeta \sin \Delta \alpha\right) \frac{1}{2 \pi} \int_{0}^{2 \pi} F_{c p} \cdot \sin \alpha d \alpha \\
& +\left(R_{2} \sin \Delta \alpha+\lambda_{2} \zeta \cos \Delta \alpha+\lambda_{1} \zeta\right) \frac{1}{2 \pi} \int_{0}^{2 \pi} F_{c p} \cdot \cos \alpha d \alpha \\
& +\left(\lambda_{1} R_{1}-\lambda_{2} R_{2} \cos (2 \Delta \alpha)\right) \frac{1}{4 \pi} \int_{0}^{2 \pi} F_{c p} \cdot \sin (2 \alpha) d \alpha \\
& -\lambda_{2} R_{2} \sin (2 \Delta \alpha) \frac{1}{4 \pi} \int_{0}^{2 \pi} F_{c p} \cdot \cos (2 \alpha) d \alpha
\end{aligned}
$$




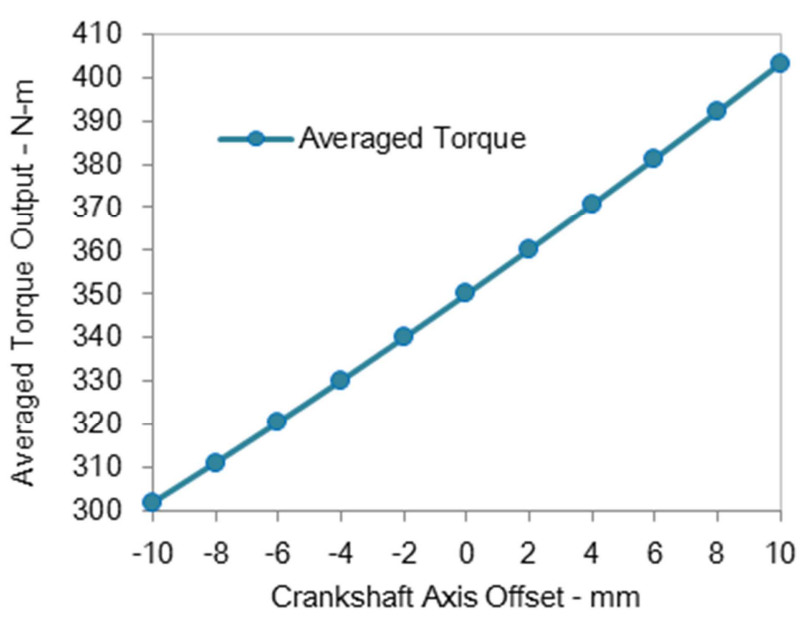

Figure 10. Crankshaft Centerline Offset versus Averaged Torque.

When the initial crank angle difference between inner crank web and outer crank web is set to $\triangle C A=0$, just as shown in Figure 10, the axis offset of crankshaft will impose a little effect on averaged torque output in a OPE diesel engine relative to the parameter of $\triangle C A$. As a result, this design variable, i.e. axis offset of crankshaft centerline, is not relatively so critical to the entire averaged torque output at flywheel end.

\section{Self-balanced Property of OPE Crankshaft System}

The crankshaft system with opposed piston layout has the possibility to counteract the forces along the cylinder axis direction, because the movement direction of both pistons always remains opposite, and reverse forces impose on each crankshaft journal by respective connecting rods. The second-order reciprocation inertial forces for both pistons can be almost removed in cylinder axis direction if meeting the below relationship in equation (12). For the detailed explanation about calculation process, it should be referenced to the literature [19].

$$
\frac{M_{g 2}}{M_{g 1}}=\frac{m_{g 2} \omega_{2}^{2} R_{2}}{m_{g 1} \omega_{1}^{2} R_{1}}=\frac{\lambda_{1}}{\lambda_{2}} \text { or } \lambda_{1} M_{g 1}=\lambda_{2} M_{g 2}
$$

where $M_{g 1}, M_{g 2}$ are the moments of inertia for inner piston and outer piston, respectively.

In formula (12), it is indicated that the prerequisite of eliminating the second-order inertia force is to make the product of inner connecting rod ratio times its inertia moment equal to the one of outer connecting rod. Once the above condition is achieved, there will be very low lateral loads (Parallel to X Axis) transferred to engine block. The force decomposition of crankshaft system is restated in Figure 11. In $\mathrm{X}$ direction, the force direction of $\mathrm{Fx}_{1}$ is contrary to $\mathrm{Fx}_{2}$ all the time, so the resultant force will be quite small, which is different from a four-stroke diesel engine with four cylinders. However, for $\mathrm{Y}$ direction, $\mathrm{Fy}_{1}$ and $\mathrm{Fy}_{2}$ both have the same force directions, thus the resultant force is the sum of both forces. The maximum magnitude of main bearing load is only about $6000 \mathrm{~N}$, much lower than the four-stroke diesel engine [4]. Finally, these forces at maximum torque output point, varied with crank angle at $2000 \mathrm{rpm}$, are shown in Figure 12 at flywheel end and in Figure 13 at freed end, respectively. The magnitude of resultant force that acts on engine block is the square root of the sum of second power for Fx and Fy in two directions. Just as shown in Figure 14, the $\mathrm{Fx}$ in $\mathrm{X}$ axis will exert much little contribution to the magnitude of resultant force.

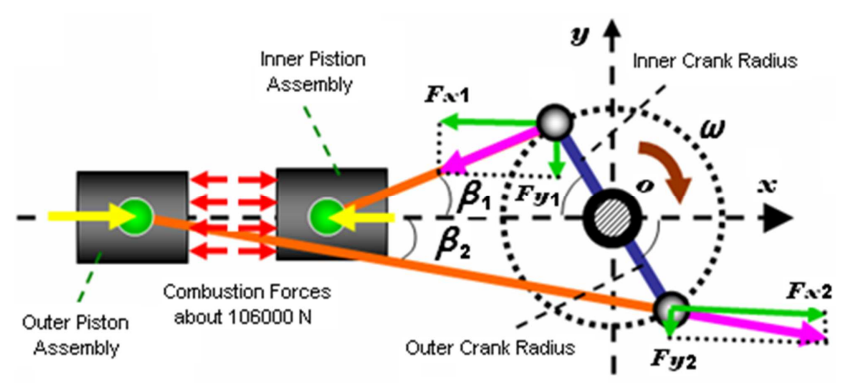

Figure 11. Force Decomposition Based on Global Coordinate System.

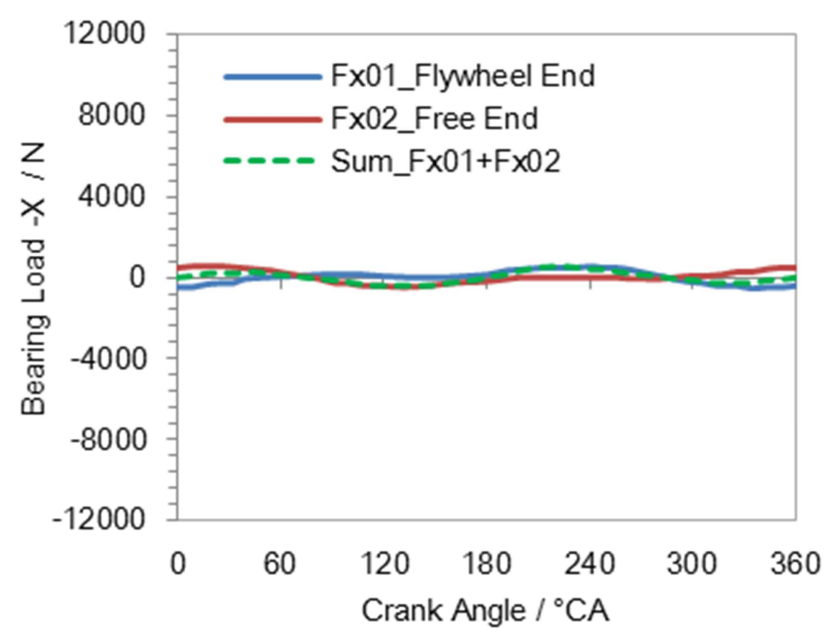

Figure 12. Force Components of Bearings in X Direction.

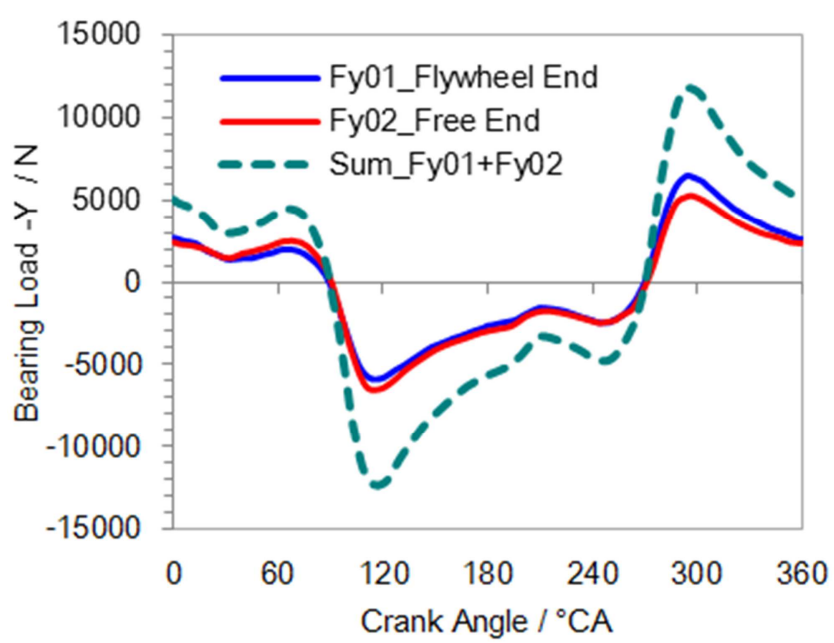

Figure 13. Force Components of Bearings in Y Direction. 


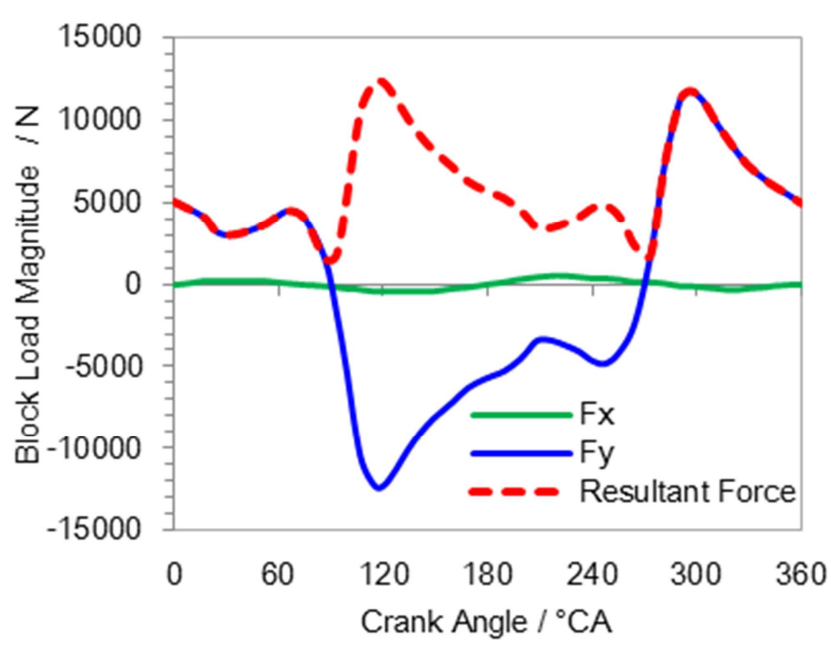

\section{Multi-body Dynamics Simulation of OPE Crankshaft System}

\subsection{Modal Reduction of Crankshaft}

In general, the time-dependent solution of finite element model is a tough task that requires a lot of simulation time and is also inefficient. Hence, it is essential to perform modal reduction for OPE crankshaft. The crankshaft solid will be discretized into numerous minor elements, which treated as a flexible body. The finite element model of OPE crankshaft assembly can be observed in Figure 15. The total mesh number of crankshaft assembly is around 300,000 cells. The $42 \mathrm{CrMoA}$ is specified as the material of crankshaft, and its main specifications all are listed in Table 1.

Figure 14. Resultant Force Acting on Engine Block.

Table 1. The Material Property of 42CrMoA.

\begin{tabular}{llll}
\hline Material Type & Elasticity Module (GPa) & Poisson Ratio (-) & Density (kg/m^3) \\
\hline \multirow{3}{*}{$42 \mathrm{CrMoA}$} & 206 & 0.282 & 7830 \\
& Yield Strength (MPa) & Ultimate Strength (MPa) & Thermal Conductivity (W/m·K) \\
\hline
\end{tabular}

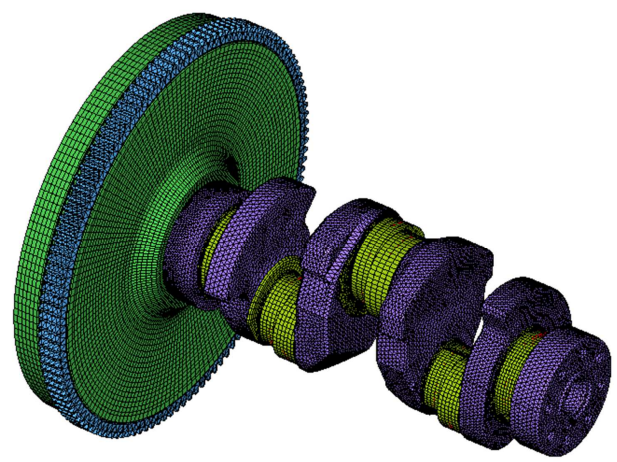

Figure 15. Mesh Model of OPE Crankshaft Assembly.

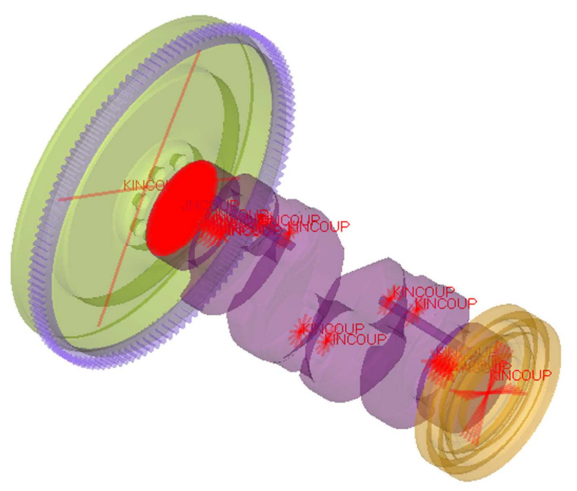

Figure 16. REB2 Definition at Crank Journals and Main Bearings.

After confirming the settings of constraints and load history, and the definition of RBE2 elements that shown in Figure 16, on the next step, it has to carry out crankshaft modal analysis, and then conduct a modal reduction to obtain

MNF (Modal Neutral File) that contains geometry, DOFs (Degree of Freedom), mass and stiffness matrix information, and then import the MNF into Adams environment by relevant FE interface. The rigid body will be automatically replaced by the flexible one. According to basic modal theory, the generated total deformation of OPE crankshaft under all types of external loading consists of each-order modal strain by linear superposition, namely modal reduction process for OPE crankshaft assembly.
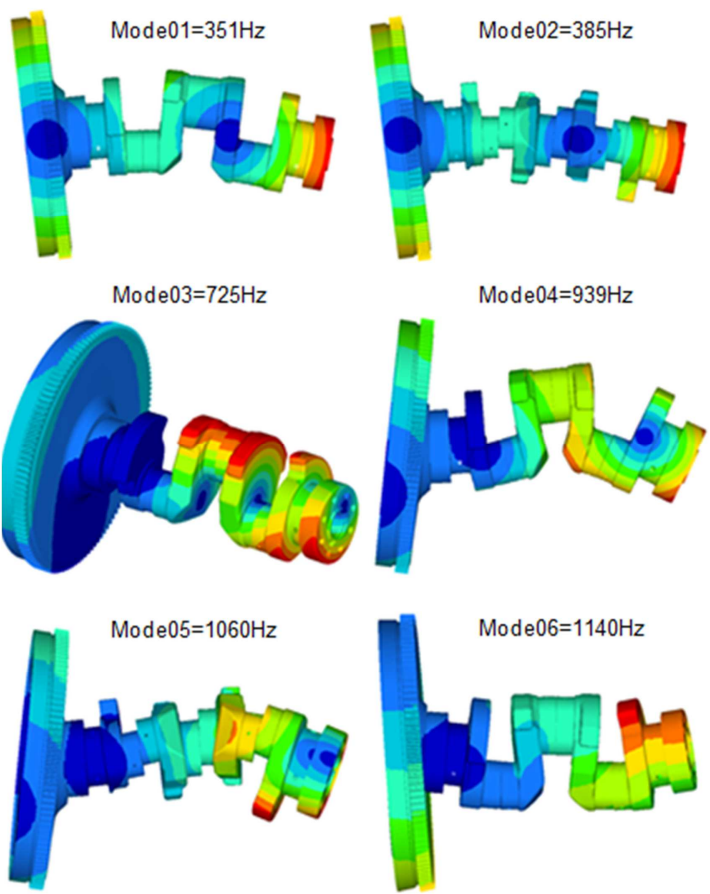

Figure 17. The First Six-order Modals of Crankshaft Assembly (Excluding

Six Rigid Modals).

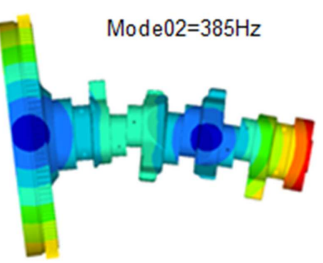

Mode $04=939 \mathrm{~Hz}$

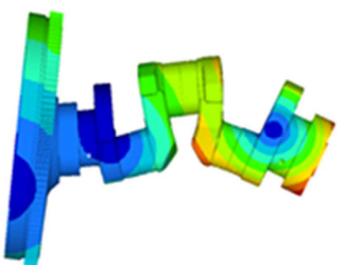


The first six-order modals solved based on OPTI-Structure module all are presented in Figure 17, which excluding six rigid modals. The mode shapes for first order and second order all are bending in a certain plane, and the third modal is characterized as torsion that is much critical to crankshaft deformation or stress concentration. It also found that concentrated regions of modal stress or strain energy density mainly are located on the transitional fillets between crank journal and crank web.

\subsection{Crankshaft Dynamic Stress and Durability}

Once the FE model of the entire crankshaft system was constructed, it becomes feasible to perform the rigid-flex coupling dynamics calculation. According to the results of crankshaft dynamics stress recovery should be implemented in order to plot the crankshaft dynamic stress (Von Mises) varied with crank angle in post-processing module. The stress concentration regions all are normally at fillets of crank journal that connected with both connecting rods. When viewing from flywheel end to free end, the maximum value occurs on the middle fillet between inner crank journal and outer crank journal. The dynamic stress contour at a certain timestamp is shown in Figure 18. Additionally, the dynamic stress curve for a critical Node with a peak stress is also depicted in Figure 19.

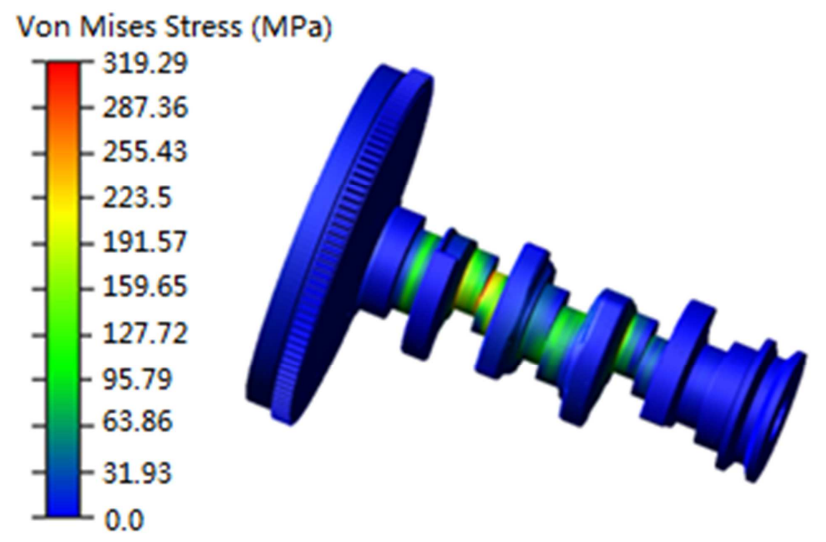

Figure 18. The Dynamic Stress Contour at a Certain Timestamp.

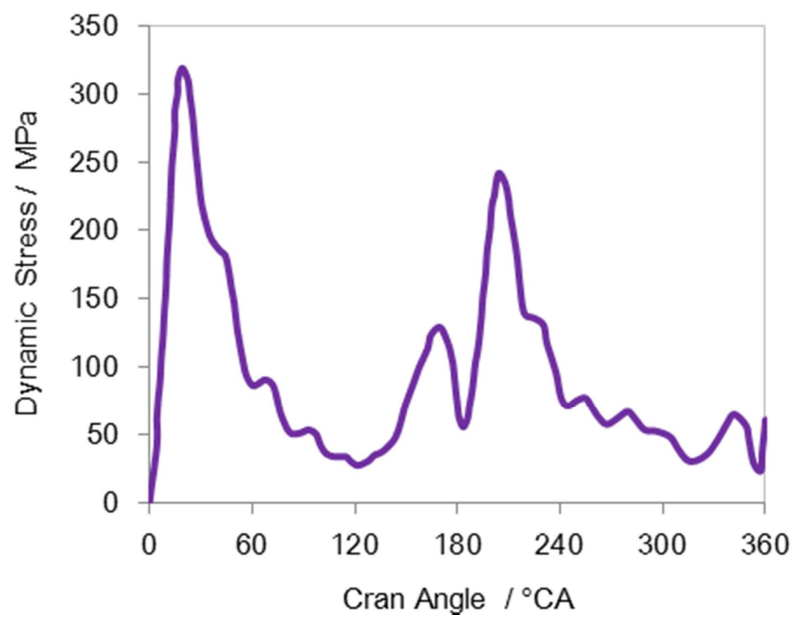

Figure 19. Dynamic Stress Curve at a Critical Node.

\subsection{Bend Fatigue Testing and Durability}

The main purpose of bend fatigue experiment is to determine the $\mathrm{S} / \mathrm{N}$ curve of crankshaft material $(42 \mathrm{CrMo})$ as the input of fatigue strength analysis. The harmonic load with a certain frequency will applied to a single crank throw during the crankshaft bending fatigue test process. The stress of crank journal fillet can be calculated based on measured strain by a strain gauge that stuck on mental surface of crank journal fillet. The installed locations of strain gauge are shown in Figure 20.

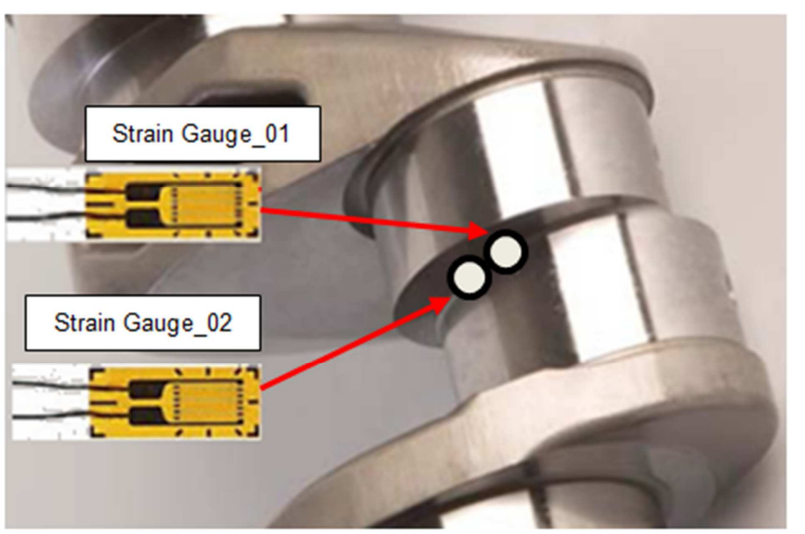

Figure 20. Strain Gauge and Equipped Positions.

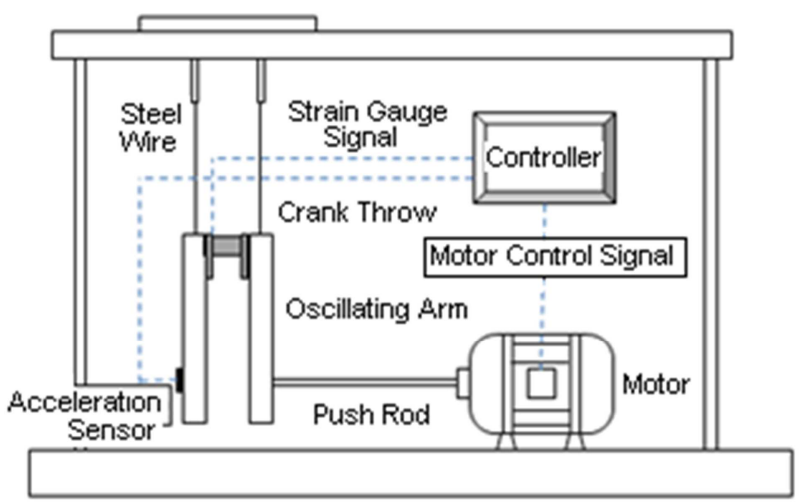

Figure 21. The Schematic of Single Crank Throw Bend Fatigue Test.
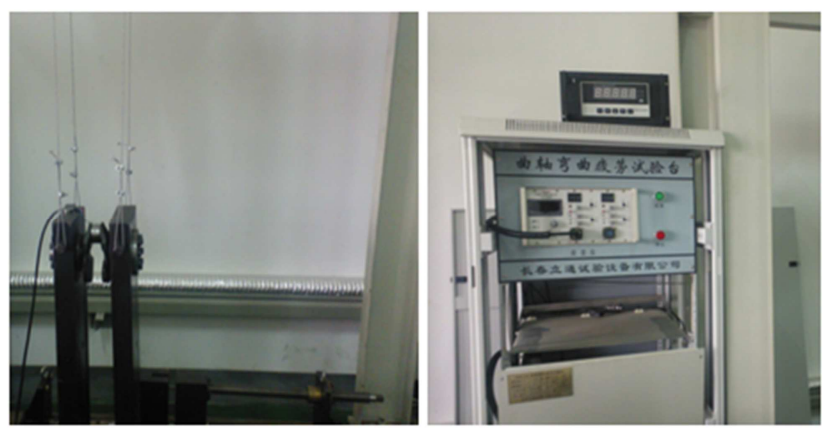

Figure 22. The Crank Throw Bend Fatigue Testing Bench.

The electromagnetic vibration motor is chosen as the power source input of this testing equipment. The vibration exciter driven by motor produces harmonic and periodic loadings acting on the push rod. Ultimately, a bending 
moment will be generated, which exerts on the single crankthrow repeatedly. The schematic of test device is described in Figure 21 and its practical testing bench is shown in Figure 22 . The S-N curves of $42 \mathrm{CrMo}$ with various heat treatments all are summarized in Figure 23.

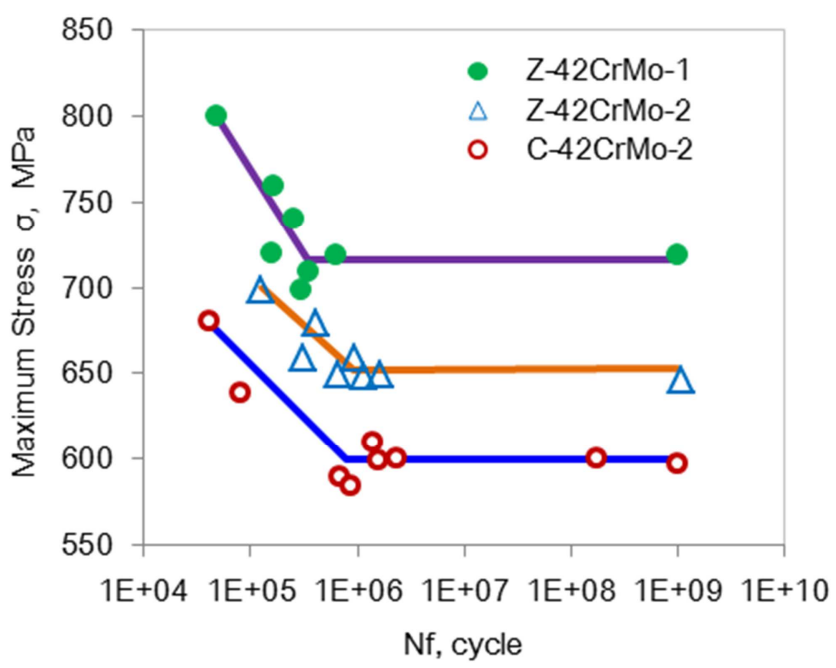

Figure 23. S-N Curves of Crankshaft Material-42CrMo.

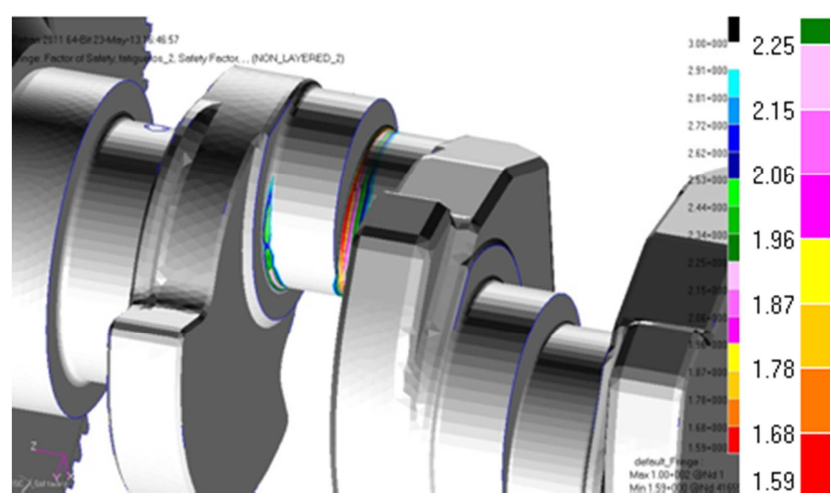

Figure 24. Safety Factor Contour on Crankshaft at 2000rpm.

In spite of the maximum Von-mises stress of crankshaft in the opposed piston engine is far less than the yield strength of material, it is still required to consider the effect of the cyclic load variation with high frequency on crankshaft fatigue lifetime. The durability evaluation of crankshaft can be regarded as a high-cycle fatigue problem. It is found that even under the worst engine operation condition, the minimum safety factor is almost up to 1.59 as shown in Figure 24, greater than relevant criterion, which meeting the design requirement, i.e. SF (Safety Factor) is higher than 1.56 with $90 \%$ survivability and $10^{7}$ cycles of design life. Actually, this optimized crankshaft did not surfer to fatigue damage throughout the prototype engine durability testing on dynamometer bench over 2000 hours.

For checking out which engine speed is most crucial, namely resonance points, the speed sweep cases will be calculated based on crankshaft dynamics simulations. The transient loads can be obtained for all bodies and joints from $1000 \mathrm{rpm}$ to $4000 \mathrm{rpm}$ under full-load operation conditions, and then the corresponding safety factors can also be obtained for all cases. The variation trend of safety factor in whole speed range is shown in Figure 25.

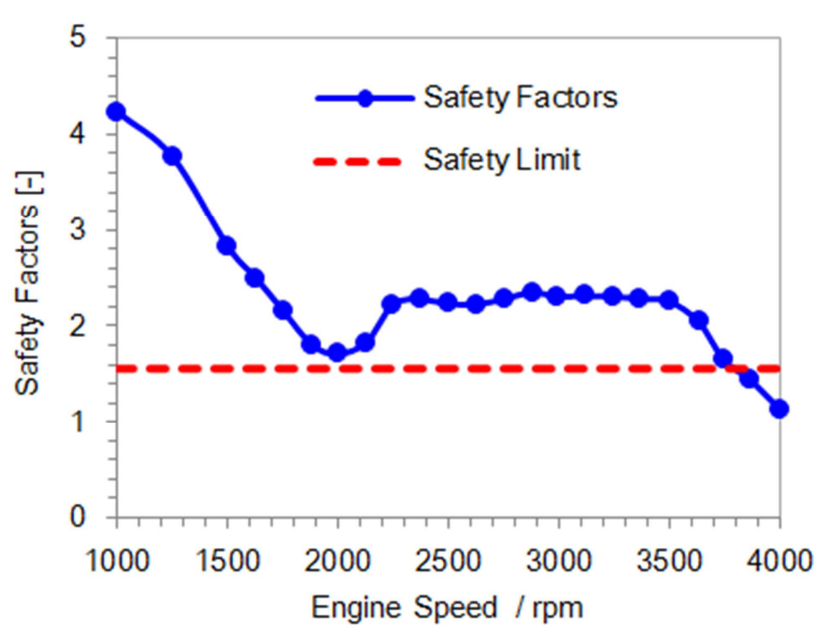

Figure 25. Engine Speed versus Safety Factor with Full Loads.

\section{Conclusions}

(1) To maximum the averaged torque output of opposed piston engine, it is proposed that the inner connecting rod length should be larger than outer connecting rod, which helpful to downsize the entire engine package while boosting the torque output as engine displacement unchanged.

(2) The initial crank angle difference has imposed a vital effect on OPE averaged torque output, but the $\triangle \mathrm{CA}$ generally needs to be limited below 30 degree for the sake of ensuring crankshaft strength, durability or geometrical model building.

(3) For the excellent self-balanced characteristics of OPE crankshaft system, there only low loads will be transferred from crankshaft to block, which much lower than a conventional four-stroke diesel engine, so that it is conducive to reduce entire engine structural noise.

(4) During the engine speed sweep from 1000rpm to 4000rpm all the minimum safety factors are above 1.56 with $90 \%$ survivability and $10^{7}$ cycles of design life The crankshaft prototype is also approved throughout the engine durability testing over 2000 hours.

\section{Definitions/Abbreviations}

$\mathrm{R}_{1}, \mathrm{R}_{2}$ : Inner and Outer Crank Radius $\mathrm{mm}$

$\beta_{1}, \beta_{2}$ : Pivot Angle

$\triangle \mathrm{CA}$ : Initial Crank Angle Difference ${ }^{\circ} \mathrm{CA}$

$\mathrm{Fcp}_{1}, \mathrm{Fcp}_{2}$ : Gas Force Acting on Inner Piston and Outer Piston N

$\mathrm{mg}_{1}, \mathrm{mg}_{2}$ : Inertia Mass of Inner Piston and Outer Piston $\mathrm{kg}$

$\mathrm{L}_{1}$ : Inner Connecting rod Length $\mathrm{mm}$

$\mathrm{L}_{2}$ : Outer Connecting rod Length $\mathrm{mm}$

$\alpha_{1}, \alpha_{2}$ : Initial Crank Angle ${ }^{\circ} \mathrm{CA}$

$\mathrm{M}, \mathrm{M}_{1}, \mathrm{M}_{2}$ : Transient Torque Output $\mathrm{N} \cdot \mathrm{m}$ 
$\mathrm{M}_{\mathrm{m}}$ : Averaged Torque Output $\mathrm{N} \cdot \mathrm{m}$

$\omega$ : Angular Velocity $\mathrm{m} / \mathrm{s}$

SF: Safety Factor

HCF: High Cycle Fatigue

OPOC: Opposed Piston and Opposed Cylinder

OP2S: Opposed Piston with 2-stroke

NVH: Noise, Vibration and Harshness

OPE: Opposed Piston Diesel Engine

MNF: Modal Neutral File

BSFC: Brake Specific Fuel Consumption

DOE: Design of Experiment

TDC: Top Dead Center

DOF: Degree of Freedom

\section{References}

[1] Laurence F., Randy H., and John K., et al., Modernizing the Opposed-piston Engine for More Efficiency Military Ground Vehicle Applications. 2012 NDIA Ground Vehicle Systems Engineering and Technology Symposium, Michigan, August, 2012, 14-16.

[2] Foster, D., Herold, R., Lemke, J., and Regner, G., et al., Thermodynamic Benefits of Opposed-piston Two-stroke Engines, SAE International Technical Paper, 2011-01-2216.

[3] Flint, M. and Pirault, J., "Opposed Piston Engines: Evolution, Use, and Future Applications," (Warrendale, SAE International, 2009), doi:10.4271/R-378.

[4] Hofbauer, P., "Opposed Piston Opposed Cylinder (OPOC) Engine for Military Ground Vehicles," SAE Technical Paper 2005-01-1548, 2005, doi:10.4271/2005-01-1548.

[5] Hofbauer, P., Stroke of Genius OPOC Takes Two. Engine Technology International, June, 1999.

[6] Xu, H. J., Song J. O, Yao C. D. and Liu C. Z., et al., Simulation on In-cylinder Flow on Mixture Formation and Combustion in OPOC engine. NeiRanJi XueBao, 27, 5, 395400 .

[7] Lee, P., and Wahl, M. (2012). Cylinder cooling for improved durability on an opposed-piston engine. SAE International Technical Paper, 2012-01-1215.

[8] Franke, M., Huang, H., Liu, J., Geistert, A. et al., "Opposed Piston Opposed Cylinder (opoc ${ }^{\mathrm{TM}}$ ) $450 \mathrm{hp}$ Engine: Performance Development by CAE Simulations and Testing," SAE Technical Paper 2006-01-0277, 2006, doi:10.4271/200601-0277.
[9] Ping, H. Analysis of Self-Balance Characteristics of OPOC Engine. Advanced Materials Research, 211-212, 93-96.

[10] Wang, Z. H., The Analysis and Comparison of Subaru and Porsche Opposed-cylinder Engine [EB/OL]. http://info.52che.com/taizhou/ news 287 653.html, August, 26, 2011.

[11] Foudray, H. and Ghandhi, J., "Scavenging Measurements in a Direct-Injection Two-Stroke Engine," SAE Technical Paper 2003-32-0081, 2003, doi:10.4271/2003-32-0081.

[12] Wojdyla, B. (2010). Ecomotors Opposed Piston Opposed cylinder (OPOC). Popular Mechanics

[EB/OL].http://www.popularmechanics.com/cars/news/fueleconomy/6-prototype-engines-to-get-your-brain-firing \#fbIndex1.

[13] Walker, J. R. Exploring Power Technology. South Holland: The Goodheart-Willcox Co., Inc.

[14] He Changming, Xu Sichuan, Zuo Chaofeng, etc. Multi-valve Intake Port Parametric Design and Performance Optimization of the Horizontal Diesel Engine, Mechanika, Vol.17 (6): 643648.

[15] Kalkstein, J., Röver, W., Campbell, B., Zhong, L. et al., "Opposed Piston Opposed Cylinder (opoc ${ }^{\mathrm{TM}}$ ) 5/10 kW Heavy Fuel Engine for UAVs and APUs," SAE Technical Paper 2006-01-0278, 2006, doi:10.4271/2006-01-0278.

[16] Fabien Redon, Christopher Kalebjian, John Kessler and Nicholas Rakovec, et al., "Meeting Stringent 2025 Emission and Fuel Efficiency Regulations with an Opposed-Piston, Light-Duty Diesel Engine," SAE Technical Paper 2014-011187, 2014, doi:10.4271/2014-01-1187.

[17] Micheal Wittler, Opposed Piston Opposed Cylinder Engine (OPOC) - Advanced Technology Development at FEV, China Internal Combustion Engine Industry Association, Aachen, February $28^{\text {th }}, 2011$.

[18] Willcox, M., Cleeves, J., Jackson, S., Hawkes, M. et al., "Indicated Cycle Efficiency Improvements of a 4-Stroke, High Compression Ratio, S. I., Opposed-Piston, Sleeve-Valve Engine Using Highly Delayed Spark Timing for Knock Mitigation,” SAE Technical Paper 2012-01-0378, 2012, doi:10.4271/2012-01-0378.

[19] Changming, H. and Sichuan, X., "The Investigation of SelfBalanced Property and Vibration on the Particular Crankshaft System for an Opposed Piston Engine," SAE Technical Paper 2016-01-1768, 2016, doi:10.4271/2016-01-1768. 